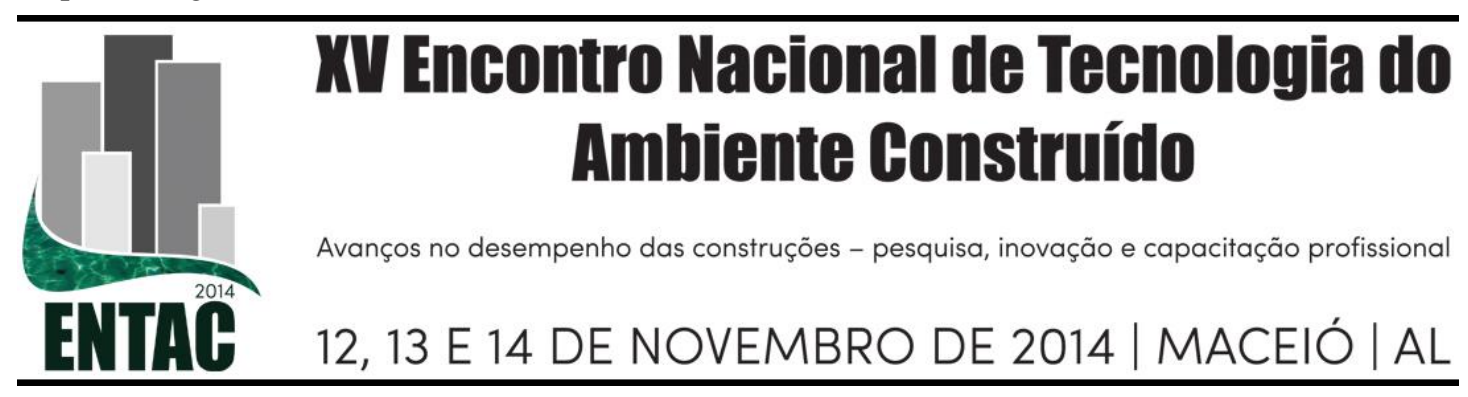

\title{
GERENCIAMENTO DE RISCOS: QUAL É O PAPEL DO PLANEJAMENTO URBANO?
}

\author{
POHLMANN, Patricia (1); PICCININI, Lívia S. (2); DA SILVA FILHO, Luiz \\ Carlos P. (3)
}

(1) ufrgs, (51) 9582 7062, e-mail: patricia.arquitetura@gmail.com (2) ufrgs, e-mail: livia.piccinini@ufrgs.br(3) ufrgs,e-mail: lcarlos66@gmail.com

\begin{abstract}
RESUMO
Este trabalho apresenta uma análise crítica sobre a integração entre a gestão de riscos e o planejamento urbano e regional. No Brasil, o crescimento urbano gera diversos impactos sobre o meio ambiente e, em decorrência disto, comunidades e sistemas urbanos são afetados por desastres naturais e consequências diversas, com intensidade e frequência cada vez maiores. Paralelamente, o aumento das desigualdades socioespaciais tem resultado na formação de áreas e comunidades vulneráveis (favelas, ocupações, irregularidade, precariedade), que são as mais afetadas pelo agravamento das mudanças climáticas e onde as populações convivem com diferentes situações de risco, tais como deslizamentos e inundações. A pesquisa discute as origens e a integração das atuais estruturas institucionais que abordam as questões de risco, relacionando sua gestão ao planejamento municipal integrado e apontando uma tomada de posição favorável à Lei $\mathrm{n}^{\mathrm{o}}$ 12.608, objeto de estudo e crítica. O enfoque adotado considera que a dificuldade de integração entre estes campos é devida à adoção do planejamento setorial que, a partir da década de 1970, passou a trabalhar, separadamente, as questões urbanas e regionais que são interligadas e deveriam ser entendidas e tratadas desta maneira. O presente artigo chama a atenção para a necessidade de considerar as questões e situações de risco como objeto e objetivo do planejamento urbano e regional. A metodologia adotada, através de um resgate histórico, relaciona os campos e conceitua as questões comuns, inserindo a gestão de riscos no processo de planejamento integrado. As conclusões pretendem gerar diretrizes que auxiliem na análise, prevenção e gerenciamento de risco que possam vir a subsidiar ações de políticas públicas que visem cidades saudáveis.
\end{abstract}

Palavras-chave: planejamento integrado, gestão de riscos, prevenção.

\begin{abstract}
This paper presents a critical analysis on the integration of risk management and urban and regional planning. In Brazil, urban growth generates different impacts on the environment, and as a result, communities and urban systems are affected by natural disasters and various consequences, with increasing intensity and frequency. In parallel, the increase in socio-spatial inequalities has resulted in the formation of vulnerable areas and communities (slums, occupations, irregularity, instability), which are the most affected by the worsening of climate change and in places where people live with many risky situations such as landslides and floods. The research discusses the origins and integration of current institutional structures that address issues of risk management, relating its management to the integrated municipal planning and pointing towards a decision-making favorable to the Law number 12.608, subject of study and criticism. The adopted approach considers that the difficulty of integration between these fields is due to the adoption of sectorial planning which from the 70's on started to work separately the issues of urban and regional planning. These areas of study are interconnected and should be understood and treated as an integrated whole. The article draws attention to these issues and stresses the need to take risk analysis and management as object and purpose of urban and regional planning. The methodology adopted through a historical perspective, conceptualizes common issues, entering risk analysis and management in the integrated planning process. The conclusions aim to generate guidelines
\end{abstract}


to assist in risk analysis, prevention and management, which may subsidize public policies aimed at healthy cities.

Keywords: integrated urban and regional planning, risk management, natural disaster prevention.

\section{O CONTEXTO DA GESTÃO DE RISCOS E A RELAÇÃO COM O PLANEJAMENTO URBANO E REGIONAL}

Este artigo surgiu a partir da experiência adquirida em um Centro de Estudos e Pesquisas sobre Desastres - CEPED/UFRGS (GRID, 2013), com foco nos desastres ${ }^{1}$ que mais afetam a região sul do Brasil: inundações e deslizamentos. Através de discussões e cursos de capacitação que tomam como foco a gestão de riscos e desastres, abordam-se de maneira empírica os problemas do processo de urbanização e seu agravamento. $\mathrm{O}$ que se mostrou mais premente nesse processo foi a necessidade de prevenção, educação ambiental e regramento sobre uso e ocupação do solo, associados ao conhecimento sobre as condições físicas do ambiente e traduzidos na Lei $\mathrm{n}^{\mathrm{o}}$ 12.608/2012 que institui a Política Nacional de Proteção e Defesa Civil, orientando as ações públicas e privadas, e, dentre outras determinações, incentiva o planejamento com base em pesquisas e estudos sobre áreas de risco e desastres e determina a adoção da bacia hidrográfica como unidade de análise das ações de prevenção de desastres. A interpretação da norma legal mostra a orientação incisiva da obrigatoriedade da associação entre o trabalho do planejamento urbano e regional às ações relacionadas à gestão de riscos, contemplando as demandas ambientais. A partir destas considerações, o presente trabalho aponta o conceito de risco e debate este conceito relacionado a inundações e deslizamentos; identifica autores e suas visões sobre o tema; questiona a integração entre os agentes que atuam em situações de desastre e apresenta a legislação. As conclusões situam a importância da ação cooperativa entre os campos do planejamento urbano e o gerenciamento de risco, já apontada na legislação, na construção de cidades resilientes e saudáveis.

\subsection{RISCO - HISTÓRICO DO RISCO COMO OBJETO DE ESTUDO}

O conceito de risco é bastante recente. Os riscos e as condições que os produzem passaram a ser considerados, a partir das transformações decorrentes da Revolução Industrial, no século XIX (FURTADO, 2012). Naquela época, foram criadas normas disciplinares e técnicas para conter a ocorrência de acidentes e garantir o controle de riscos, assim como controlar questões sanitárias que provocavam pestes e epidemias devido às más condições das moradias proletárias urbanas. Atualmente, os discursos sobre riscos incluem, além da interpretação ampla da vida na sociedade de risco, os aspectos técnicos, sociais, culturais e o entendimento diretamente relacionado com a construção da memória social e da forma como a sociedade percebe o que é risco: a percepção de riscos.

Diversos autores passaram a abordar o conceito a partir da década de 1990, como o conceito utilizado pelo WorldRiskIndex (2004) e baseado em pesquisas sobre riscos e desastres naturais, onde a vulnerabilidade engloba as condições determinadas por

\footnotetext{
${ }^{1}$ Desastres: resultados de eventos adversos, naturais ou provocados pelo homem, sobre um ecossistema vulnerável, causando danos humanos, materiais ou ambientais e consequentes prejuízos econômicos e sociais (BRASIL, 2010).
} 
fatores físicos, sociais econômicos e ambientais, ou processos que são refletidos na suscetibilidade $^{2}$, na capacidade de enfrentamento e na adaptação:

Risco é o produto das interações entre perigos naturais ou induzidos pelo homem e as condições vulneráveis, incluindo a probabilidade de ocorrência de fenômenos de risco. (UNISDR, 2004, Birkmann 2006; Cardona, 2003)

A adaptação se refere principalmente às estratégias de mudanças da sociedade no longo prazo e a condição de enfrentamento se refere à resposta imediata aos problemas gerados por processos naturais (UNISDR, 2004).

Desta forma, o risco e a percepção de riscos são resultados de construções sociais, tendo uma dimensão física, subjetiva e multidimensional (FURTADO, 2012). Os dois termos configuram conceitos sobre como cada comunidade constrói sua percepção coletiva a respeito de determinado fenômeno, resultado do grau de resiliência ${ }^{3}$ às situações de risco a que está exposta. Esta percepção coletiva de risco vem amadurecendo ao longo da sociedade industrial, tomando a denominação de "desastres" na Segunda Guerra Mundial, quando foram realizadas as primeiras ações, estruturas e estratégias de proteção e segurança dirigidas à população. Após os efeitos dos bombardeios sofridos pelas principais cidades e centros industriais ingleses, entre 1940 e 1941, a preocupação com a segurança da população levou a Inglaterra a criar a Civil Defense (BRASIL, [201-]), com o objetivo de garantir segurança e justiça à população.

No Brasil, órgão semelhante, o Serviço de Defesa Civil Passiva Antiaérea foi criado em 1942, após o afundamento de navio militar brasileiro por submarino alemão, no litoral da Bahia. O Serviço de Defesa Civil, que tinha como objetivo o ensino da defesa passiva, nas escolas do país, foi extinto em 1946. Em 1966, em função de fortes chuvas na região Sudeste, que provocaram enchentes no então Estado da Guanabara (RJ) e deslizamentos na Serra das Araras (SP), foi criada a Defesa Civil no Estado da Guanabara. Em 1967, ainda em consequência destes eventos, foi criado o Ministério do Interior com a competência de assistir populações atingidas por calamidades públicas ${ }^{4}$.

Desde a criação dos órgãos de Defesa Civil, as ações no Brasil, foram desenvolvidas para atuar na assistência a situações de emergência ${ }^{5}$ e/ou calamidade pública, ou seja, após o desastre ocorrido. Apenas em 1988, surge a proposta de pensar a Defesa Civil ${ }^{6}$ como instituição para redução de riscos de desastres, a partir da organização do Sistema Nacional de Defesa Civil, com o Decreto n ${ }^{\circ} 97.274$ de 16 de dezembro de $1988^{7}$. Este conceito, de reduzir os riscos de desastres, é reforçado com a aprovação da Resolução

\footnotetext{
${ }^{2}$ Suscetibilidade: se refere às condições de comunidades expostas ou elementos expostos (infraestruturas, ecossistemas, etc) que se tornam mais propensos a experimentar danos e ser afetados negativamente por um desastre natural ou pelas mudanças climáticas (UNISDR, 2004).

${ }^{3}$ Resiliência: significa a habilidade de um sistema, comunidade ou sociedade exposta a riscos de resistir, absorver, acomodar-se, e reconstruir-se diante dos efeitos de um desastre em tempo e modo adequados, incluindo a preservação e restauração de suas estruturas e funções essenciais (UNISDR, 2009).

${ }^{4}$ Estado de calamidade pública: situação anormal, provocada por desastres, causando danos e prejuízos que impliquem o comprometimento substancial da capacidade de resposta do poder público do ente atingido (Brasil, 2010).

5 Situação de emergência: situação anormal, provocada por desastres, causando danos e prejuízos que impliquem o comprometimento parcial da capacidade de resposta do poder público do ente atingido (Brasil, 2010).

${ }^{6}$ Defesa Civil: conjunto de ações preventivas, de socorro, assistenciais e recuperativas destinadas a evitar desastres e minimizar seus impactos para a população e restabelecer a normalidade social (Brasil, 2010).

${ }^{7}$ Revogado em 1993 pelo Decreto $\mathrm{n}^{\circ} 895$ de 2005 que foi revogado novamente em 2010 pelo Decreto $\mathrm{n}^{\circ}$ 7.257 de 2010.
} 
44/236 na Assembleia Geral da ONU, estabelecendo o ano de 1990, como início da Década Internacional para Redução dos Desastres Naturais ${ }^{8}$ (DIRDN). A partir da década de 1990, o pensamento internacional evolui e, em 2002, é criada pelas Nações Unidas, a Estratégia Internacional para a Redução de Desastres (ISDR), com o objetivo de promover "a emergência de uma cultura de prevenção baseada na redução das vulnerabilidades", através da estruturação de Plataformas Nacionais interligadas globalmente por rede (RODRIGUES, 2010).

Após o estabelecimento da DIRDN, foi elaborado um plano nacional de redução de desastres para a década de 1990, conhecido como Política Nacional de Defesa Civil que passou a reestruturar órgãos federais (criação da SEDEC $^{9}$ ), organizar manuais de planejamento em Defesa Civil, capacitar técnicos em desastres e estruturar bancos de dados com classificação dos desastres específicos da realidade brasileira (BRASIL, [201-]). Estas e outras ações e acontecimentos (Figura 1), culminaram com a Lei Federal n ${ }^{\circ} 12.608$ de 2012 que instituiu a Política Nacional de Proteção e Defesa Civil (PNPDEC), envolvendo ações de quatro Ministérios ${ }^{10}$, o que representa, além da importância da integração de políticas multisetoriais, uma revisão das principais legislações urbanísticas nacionais, resultando em alterações que passam a considerar o risco no planejamento das cidades.

Figura 1 - Histórico dos principais acontecimentos relacionados à Gestão de Riscos

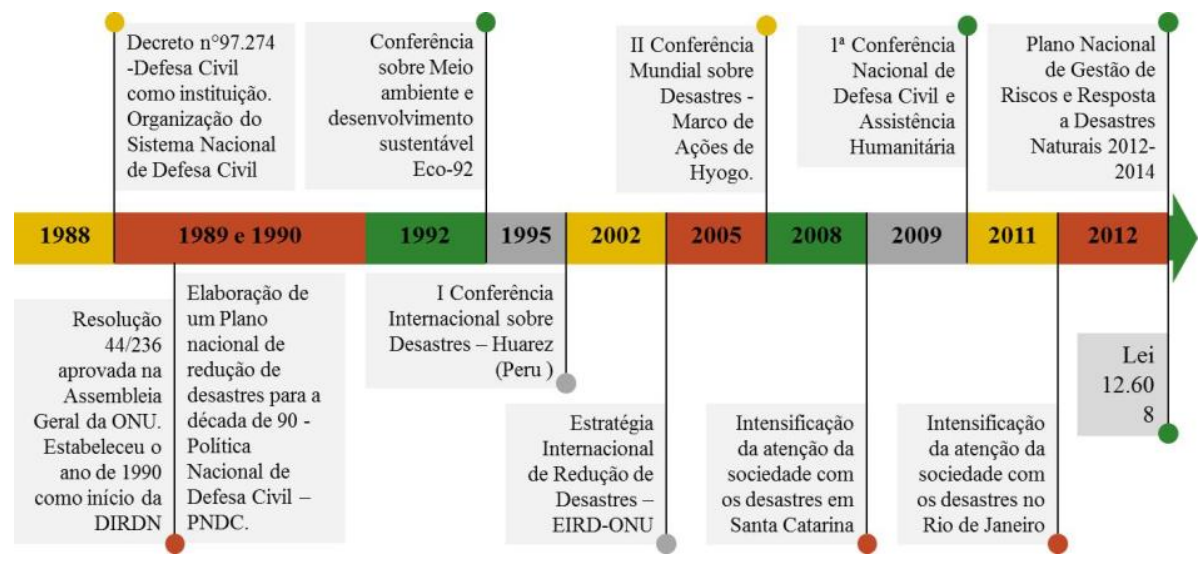

Fonte: Elaborado pela autora para GRID (2013)

\section{A IMPORTÂNCIA DA GESTÃO DE RISCOS NO PLANEJAMENTO URBANO: INTEGRAÇÃO E OBJETIVOS}

A gestão de riscos está relacionada à busca de soluções e resultados positivos para a qualidade de vida das populações urbanas e à diminuição dos transtornos e danos materiais e humanos, causados aos moradores das cidades. Estes danos e transtornos são agravados pelas mudanças climáticas, que estão sendo intensificadas pelas intervenções no ambiente natural, em um círculo vicioso que precisa ser rompido. Tomando o conceito de desenvolvimento sustentável, definido pela Commission on Environmental and Development (WCED), como "o desenvolvimento que satisfaz as necessidades do

\footnotetext{
${ }^{8}$ Década Internacional para Redução dos Desastres Naturais (DIRDN): o objetivo central da campanha era a redução de perdas de vidas, danos e transtornos socioeconômicos, provocados por desastres naturais principalmente nos países em desenvolvimento (BRASIL, [201-]).

${ }^{9}$ SEDEC: Secretaria Nacional de Proteção e Defesa Civil.

${ }^{10}$ Ministério das Cidades, Ministério de Integração Nacional, Ministério de Ciência e Tecnologia e Ministério de Minas e Energia.
} 
presente sem comprometer a capacidade do futuro para atender a sua própria necessidade" e incorporando a proposta de Lyle (1994) de considerar parâmetros de comportamento do meio ambiente nos projetos do ambiente construído, ampliando a discussão sobre a necessidade de mudanças de comportamento na interação entre o ambiente natural e o homem, e ainda, incorporando a ideia de projetos regenerativos na construção do ambiente construído, identifica-se a necessidade de previsão das alterações no ambiente natural devidas à ocupação urbana. Por um lado, pouco tem avançado, o planejamento urbano, no trato da problemática do risco e, por outro lado, identifica-se a falta de conhecimento específico, sobre os aspectos da urbanização, aos que trabalham com a "gestão de riscos". Temos aqui uma separação dos conhecimentos e abordagens, que precisam estar interligados, re-instituindo o planejamento de longo prazo e que incorpore as necessidades referentes à gestão do risco em sua agenda. A Figura 2 representa a multisetorialidade da gestão de riscos e sua articulação com os diversos setores que devem estar integrados nesta discussão.

Figura 2 - Multissetorialidade da gestão de riscos

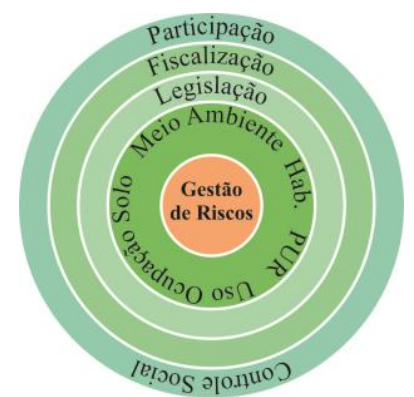

Fonte: GRID (2013)

Compreende-se, assim, a importância do planejamento urbano e regional (PUR) nesta discussão, pois um dos quatro pilares que estruturam a Política Nacional de Proteção e Defesa Civil é a prevenção de desastres, e prever e prevenir é um dos papeis designados e assumidos pelo planejamento urbano e regional. Por isso, além de buscar identificar qual o papel do planejamento urbano e regional na gestão de riscos, o objetivo deste artigo é verificar onde, dentro das atuais estruturas que abordam a gestão de risco, o planejamento urbano está localizado. Tradicionalmente, o papel que o PUR tem exercido é o de planejar e integrar as ações entre os diversos setores (infraestrutura, habitação, meio ambiente, saneamento, etc.) assim como $o$ de orientar 0 desenvolvimento sócio-espacial. O planejamento setorial, iniciado na década de 70, está associado aos atuais órgãos estaduais de Defesa Civil, que igualmente trabalham de forma setorial. Assim, para demonstrar a importância da introdução do termo "integrado" como conceito-guia da discussão, principalmente ao insistir na urgência de ações integradas do planejamento na proteção dos ambientes e das populações, é essencial demonstrar a influência que um campo disciplinar exerce sobre o outro, assim como, a recente tentativa, traduzida pela Lei $\mathrm{n}^{\circ}$ 12.608/2012, de retomar a integração entre os diferentes setores e campos.

\section{A CONTRIBUIÇÃO DO PLANEJAMENTO INTEGRADO PARA A GESTÃO DE RISCOS}

A gestão de riscos é uma área de conhecimento recente e tem realizado consideráveis esforços para atuar entre os setores que decidem as ações sobre os territórios urbanos e regionais e exercem influência no ambiente construído. Estes esforços foram consolidados na Lei $\mathrm{n}^{\mathrm{o}}$ 12.608/2012 que aponta a necessidade da integração entre as 
políticas de ordenamento territorial com as políticas de gestão de riscos. A lei representa a busca por transformações e mudanças nos procedimentos, projetos e ações que, desde a década de 1970, vinham ocorrendo separadamente tanto nas ações de prevenção de risco, quanto nas propostas do planejamento urbano e regional. Em 2003, com o Ministério das Cidades, tentativas de integração entre políticas públicas urbanas passam a ser retomadas, considerando o uso e a ocupação do solo. Especificamente sobre a prevenção de riscos, foi criado em 2003 o Programa Urbano de Prevenção e Erradicação de Riscos, que instituiu, pela primeira vez, o assessoramento aos municípios para o planejamento da redução de casos de escorregamentos em encostas, erosão e enxurradas (BRASIL, [201-]). Este movimento trouxe o apoio técnico-financeiro do Governo Federal aos municípios que apresentam áreas de risco, promovendo capacitação técnica e disponibilizando conhecimento em gerenciamento de riscos, tanto em âmbito local como através da articulação entre as três esferas do governo. Além deste programa, está em desenvolvimento o Plano Nacional de Prevenção a Desastres Naturais 2012-2014, que contempla o mapeamento de riscos a inundações e deslizamentos nos municípios que apresentam maiores riscos relacionados a estes fenômenos (BRASIL, 2011). O mapeamento de riscos compõe o diagnóstico da área afetada e significa o primeiro conjunto de estudos para a análise da situação atual, tornando-se importante ferramenta para o planejamento, tanto das ações sobre risco como para o planejamento urbano e regional.

Estas determinações legais demonstram o incentivo ao desenvolvimento do conhecimento sobre a percepção de riscos, uma constatação do amadurecimento da sociedade brasileira, que passa a incluir as questões de risco como prioridade na agenda do país. A percepção de riscos vem sendo despertada pela ocorrência de grandes e frequentes acidentes, incluídos como problemas da "crise urbana" e que permearam as primeiras discussões e demandas pela Reforma Urbana ${ }^{11}$.

Até o final da década de 1980 as ações realizadas para o atendimento do risco eram desenvolvidas em âmbito local e basicamente relacionadas à resposta ao desastre e à mitigação dos danos. Estas ações estavam concentradas na Defesa Civil e realizadas via obras de engenharia civil, não havendo planejamento de cenários futuros para evitar possíveis desastres. Com a Constituição Federal de 1988, que cria um capítulo sobre política urbana, o reordenamento da gestão de risco nos níveis estaduais e municipais foram sendo desenvolvidos e, paralelamente, foram surgindo importantes contribuições do meio técnico-científico para o melhor entendimento do ambiente físico e das interferências antrópicas, e a revisão e elaboração de nova legislação e disposições urbanísticas vem se consolidando.

Uma das contribuições pioneiras do meio técnico-científico para o aumento da percepção de riscos, é o Plano Integrado de Engenharia Ambiental, na cidade mineira de Juiz de Fora, MG (MATTES et al., 1986) assim como o Mapeamento de Riscos das Favelas em São Paulo (CERRI \& CARVALHO, 1990), além de trabalhos posteriores que, desde 1990 apontam a importância da percepção de risco na análise ambiental. Na Década Internacional para Redução de Desastres Naturais-1990 (DIRDN), diversos simpósios e seminários aconteceram envolvendo a temática de riscos relacionados à geologia ou à engenharia. Sob o enfoque urbano, a Eco-92 pode ser citada como um dos principais acontecimentos relacionados à questão urbana, onde a Conferência sobre

\footnotetext{
${ }^{11}$ Em 1963 foi realizado o Seminário de Habitação e Reforma Urbana (SHRU) no Hotel Quitandinha no Rio de Janeiro. O SHRU foi promovido pelo Instituto de Arquitetos do Brasil e gerou várias propostas para a nova política habitacional e urbana que foram retomadas após a ditatura militar na redemocratização a partir do processo Constituinte de 1988 (VITRUVIUS, 2010).
} 
Defesa Civil tratou da relação entre as grandes cidades e a redução de riscos. A Eco-92 foi importante na temática urbana, pois resultou na Agenda 21 cujo objetivo é, no nível dos assentamentos humanos (Capitulo 7), o Desenvolvimento Sustentável das Cidades (BRASIL, 1995). Estas contribuições iniciais relacionadas a riscos, surgem como movimentos educativos em relação à ocupação sustentável do ambiente natural, das cidades e em relação à percepção de riscos. Nesse contexto, o papel do planejamento urbano como integrador desses diversos âmbitos (territorial, habitacional, social, econômico, etc.) é manifesta, o que tende a ampliar os debates sobre os problemas urbanos e incorporar as questões de risco nos planos urbanísticos, com o objetivo de garantir a sustentabilidade ambiental.

O Estatuto da Cidade, também de forma educativa, reafirma a garantia do direito a cidades sustentáveis e a necessidade de consideração dos efeitos negativos causados ao meio ambiente pelo crescimento urbano. É importante retomar o histórico do Ministério das Cidades na temática de riscos com o Programa Urbano de Prevenção e Erradicação de Riscos que apoia, através de capacitação, os municípios brasileiros na elaboração de Planos de Redução de Riscos. Este programa busca definir prioridades e estratégias, particulares para cada região e município, para evitar a ocorrência de mortes durante os períodos chuvosos mais intensos, beneficiando as pessoas que moram em favelas localizadas em encostas, em loteamentos irregulares e outras ocupações precárias com ações de prevenção. Essas ações, embora focadas especificamente nas áreas de risco, resultam positivas para as cidades de maneira ampla. O Departamento de Assuntos Fundiários Urbanos e Prevenção de Riscos (Mcidades) executa, além dos programas de regularização fundiária (Ação 8866) no Programa 2040-Gestão de Riscos e Resposta a Desastres, o Planejamento e Monitoramento da Ocupação Urbana em áreas suscetíveis a inundações e deslizamentos (Ação 20NN) e o Apoio ao Planejamento e Execução de Obras de Contenção de Encostas (Ação 8865) (BRASIL, 2013).

Após este breve resgate histórico da construção de legislação e de ações sobre a gestão de riscos e sua relação com planejamento urbano, é necessário retomar as atribuições da Defesa Civil assim como descrever o desenvolvimento das principais discussões a respeito dos riscos, nestas instituições, neste momento.

\section{A DEFESA CIVIL E OS RISCOS}

Como já mencionado anteriormente a Defesa Civil tem suas origens ligadas ao conhecimento militar e à defesa da população civil, não tendo tradicionalmente, como um de seus instrumentos, o planejamento de ações e o mapeamento de riscos. Este campo sofre outra limitação que é a inexistência de funções e cargos efetivos, na administração pública, que tratem da Defesa Civil, o que gera as situações nas quais os técnicos envolvidos com trabalhos sobre riscos, geralmente acumulam funções ao prestar apoio aos órgãos de Defesa Civil. Na maioria dos municípios brasileiros, os órgãos responsáveis pela Defesa Civil são as Coordenadorias Municipais de Defesa Civil (COMDEC). Tais organismos são compostos por membros da administração pública que atuam nas diversas secretarias municipais e apresentam grande transversalidade, pois as ações realizadas podem ser entendidas como uma ponte de ligação entre os diferentes setores de uma municipalidade. $\mathrm{Na}$ maioria dos casos esta ligação é realizada através do contato direto entre os técnicos, carecendo de uma burocracia responsável pelo desenvolvimento de procedimentos padronizados na execução de ações. O problema que deve ser evidenciado aqui é a necessidade de formação técnica, elaboração de conhecimento e de respaldo político-administrativo para os profissionais envolvidos para que as políticas públicas, assim como as ações de 
gestão de riscos, possam ter continuidade e eficiência e os profissionais sejam incentivados a atuar e a pesquisar nesse campo com efetivo apoio institucional e reconhecimento por parte das comunidades.

Um dos locais de maior representatividade para a discussão dos temas relacionados à gestão de riscos e para o planejamento das ações entre os técnicos da Defesa Civil e a comunidade científica tem sido as Conferências de Defesa Civil. A $1^{a}$ Conferência Nacional de Defesa Civil e Assistência Humanitária ocorreu em 2009, apresentando como principais avanços a capacitação dos técnicos da defesa Civil; a criação de Centros de Pesquisa; o Mapeamento das Áreas de Riscos; a realização de simulados de preparação para desastres; o Programa Redução de Riscos nas Escolas Brasileiras; a criação do Centro Nacional de Gerenciamento de Riscos e Desastres (CENAD); a transferência de recursos de socorro e assistência (Cartão de Pagamento de Defesa Civil), além de outras propostas que culminaram com a criação da Lei ${ }^{\circ}$ 12.608/2012 (BRASIL, [201-]. Instituindo a Política Nacional de Proteção e Defesa Civil (PNPDEC) a lei promove a integração entre as políticas de ordenamento territorial com as políticas de gestão de riscos e, como novo marco legal, afirma a necessidade de resgatar o planejamento integrado no enfrentamento real dos problemas urbanos, onde as questões de risco tem participação significativa.

A PNPDEC aborda temas que envolvem desde o desenvolvimento ambiental até a habitação, incidindo nas principais legislações urbanas e de moradia do país, pois está relacionada à política urbana e habitacional. Desta forma, esta lei altera o Estatuto da Cidade (Lei $\mathrm{n}^{\mathbf{0}} 10.257 / 2001$ ) e a Lei de Parcelamento do Solo Urbano (Lei $\mathrm{n}^{\mathbf{o}}$ 6.766/1979), refletindo basicamente a incorporação de ações de proteção e defesa civil no planejamento municipal, afirmando a competência dos municípios na fiscalização das áreas de risco de desastres e de vedar novas ocupações nessas áreas (BRASIL, 2012). A lei, portanto, devera resultar na adequação dos Planos Diretores para atender a estas exigências legais. A PNPDEC abrange também ações de prevenção, mitigação, preparação, resposta e recuperação voltadas à proteção e defesa civil, devendo integrarse às políticas de ordenamento territorial, desenvolvimento urbano, saúde, meio ambiente, mudanças climáticas, gestão de recursos hídricos, geologia, infraestrutura, educação, ciência e tecnologia e às demais políticas setoriais, tendo em vista o desenvolvimento sustentável (BRASIL, 2012), o que mostra a necessidade da integração entre as políticas de ordenamento territorial com as políticas de gestão de riscos.

Para reforçar a argumentação a respeito da importância do planejamento integrado, comparecem, aqui, conceitos de planejamento e também de planejamento integrado. Conforme descrito por Ferrari (1991):

Planejamento é um método de aplicação, contínuo e permanente, destinado a resolver, racionalmente, os problemas que afetam uma sociedade situada em determinado espaço, em determinada época, através de uma previsão ordenada capaz de antecipar suas ulteriores consequências.

Tal colocação, com foco da prevenção de desastres volta-se a evitar danos futuros às populações e sistemas urbanos. O conceito de planejamento integrado permite, então, visualizar uma possibilidade metodológica que abrange as problematizações elencadas pela gestão de risco e que estão diretamente relacionadas com as vulnerabilidades encontradas nas comunidades. O planejamento integrado, segundo Ferrari (1991), deve ser tanto horizontal, envolvendo os aspectos econômicos, sociais, físico-territoriais e institucionais da realidade a ser planejada; como vertical, obedecendo às metas e 
diretrizes dos planos da região envolvida, do Estado e da União. Quando o planejamento é realizado observando-se esses dois sentidos de integração, diz-se que é integrado (FERRARI, 1991). Essa conceituação de planejamento, desenvolvida nos anos 70, contempla uma demanda atual de re-integração das ações do planejamento e é aqui resgatado pois serve aos objetivos do debate aqui colocado: a integração entre o planejamento urbano e regional e a gestão de risco.

Verifica-se que a Lei $\mathrm{n}^{\circ} 12.608 / 2012$ promove os dois sentidos necessários para essa integração. Em um sentido horizontal, a necessidade de mapeamento de riscos nos municípios incluídos no cadastro nacional de municípios ${ }^{12}$ com áreas suscetíveis à ocorrência de deslizamentos de grande impacto, inundações bruscas ou processos geológicos ou hidrológicos correlatos. Em sentido vertical com a estruturação das entidades municipais, estaduais e federal visando a integração das informações e dos conhecimentos relacionados a riscos. Esta integração vem sendo desenvolvida pelo CEPED/UFRGS, e uma de suas formas metodológicas é o mapeamento de vulnerabilidade, que contempla, dentre outros, os aspectos econômicos, sociais, físicoterritoriais e institucionais, na análise. Estes procedimentos são propostos para serem aplicados aos municípios cadastrados e as perspectivas são de que outras metodologias sejam desenvolvidas para o mapeamento de riscos, contemplando, além da vulnerabilidade da área, a suscetibilidade ao perigo.

\section{CONCLUSÃO E POSSIBILIDADES FUTURAS DA PESQUISA}

O aumento da percepção de riscos da comunidade de pesquisadores brasileira intensificou as ações do Governo Federal em relação às políticas de gestão de riscos e de ordenamento territorial. Esta percepção, que vem sendo aperfeiçoada, juntamente com a necessidade de melhores critérios para a decisão sobre ocupação de áreas urbanas trazidos, à luz da lei $n^{\circ} 12.608 / 2012$, são importantes ganhos, principalmente para quem é afetado pelos desastres naturais. Estes ganhos, em consequência, são revertidos em melhor qualidade de vida para a população e mais saúde das cidades, além de aumentar o desempenho econômico para os investimentos públicos.

No entanto, é necessário um ainda maior aperfeiçoamento e união de esforços para materializar os objetivos estipulados na Lei. Será necessário desenvolver o conhecimento e a atuação integrada em ambas as áreas, planejamento urbano e gestão de riscos, que até o momento vem demonstrando dificuldade na atuação cooperativa. Além disso, a carência de pesquisas e literatura especializada, relacionadas à gestão de riscos em integração ao planejamento, requer a assistência da pesquisa empírica com o objetivo de garantir a segurança na produção de políticas públicas informadas e embasadas na realidade do país.

Assim, a caracterização de áreas suscetíveis a desastres e o constante registro de ocorrências que contem a história do local, evitando decisões equivocadas, é um impositivo, sobretudo dadas as condições climáticas e geomorfológicas específicas de municípios e regiões, no entanto, a maioria dos municípios brasileiros carece de bancos de dados estruturados que contemplem o histórico de ocorrências, instrumento poderoso para a pesquisa e o diagnóstico antecipado de riscos e desastres.

Como perspectivas futuras para esta pesquisa, um desafio será a adequação dos Planos Diretores municipais à Lei 12.608/2012, que determina o mapeamento de riscos e a

12 Cadastro Nacional de municípios prioritários: cadastro inclui 821 municípios brasileiros que apresentam suscetibilidade a deslizamentos e inundações e precisam elaborar o mapeamento de riscos. 
elaboração de cartas geotécnicas; a elaboração de plano diretor para os municípios incluídos no cadastro nacional de municípios com áreas suscetíveis a ocorrência de deslizamentos de grande impacto, inundações bruscas ou processos geológicos ou hidrológicos instáveis. Este desafio requer respostas ao questionamento aqui colocado quanto às ações cooperativas entre a gestão de riscos e o planejamento integrado. Nesse sentido, abre-se um cenário de potencialidades positivas no enfrentamento de um dos problemas a serem enfrentados pelos moradores urbanos: os riscos de inundação e deslizamentos.

\section{REFERÊNCIAS}

BRASIL. Agenda 21 - Capítulo VII. Brasília: Câmara dos Deputados, Coordenação de Publicações, 1995.

BRASIL, Decreto $\mathbf{n}^{\mathbf{0}} \mathbf{7 . 2 5 7}$, de 4 de agosto de 2010. Brasília, 2010. Disponível em: <http://www.planalto.gov.br/ccivil_03/_Ato2007-2010/2010/Decreto/D7257.htm\#art17> Acesso em: fevereiro de 2014.

BRASIL, Histórico da Defesa Civil. Brasília. Brasília, [201-]. Disponível em: <http://www.integracao.gov.br/historico-sedec> Acesso em: fevereiro de 2014.

BRASIL, Departamento de Assuntos Fundiários Urbanos e Prevenção de Riscos.

Ministério das Cidades. Brasília, [201-]. Disponível em:

$<$ http://www.cidades.gov.br/index.php/prevencao-e-erradicacao-de-riscos/820apresentacao.html> Acesso em: fevereiro de 2014.

BRASIL, $1^{\text {a }}$ Conferência Nacional de Defesa Civil e Assistência Comunitária. Brasília, [201-]. Disponível em: <http://www.mi.gov.br> Acesso em: fevereiro de 2014.

BRASIL. Plano Nacional de Gestão de Riscos e Respostas a Desastres Naturais, 2012-2014. Brasília, 2011. Disponível em: <http://www.pac.gov.br> Acesso em: agosto de 2013.

FURTADO, J. R. Gestão de riscos de desastres. Florianópolis: CEPED UFSC, 2012.

GRID, Gestão de Riscos de Desastres. Mapeamento de vulnerabilidade de áreas suscetíveis a inundações e deslizamentos em 8 municípios do Rio Grande do Sul. Porto Alegre, 2013atual. Disponível em: <http://www.ufrgs.br/grid> Acesso em Fevereiro de 2014.

FERRARI, Celson. Curso de planejamento municipal integrado. São Paulo: Pioneira, 1991.

LYLE, John Tillman. Regenerative design for sustainable development. New York - NY, 1994.

RODRIGUES, Teresa. A estratégia internacional de redução de desastres. Revista Territorium, $\mathrm{n}^{\circ}$ 17, Riscos, ISBN: 0872- 8941. Lousã (PORTUGAL), 2010. Disponível em: $<$ http://www.uc.pt/fluc/nicif/riscos/Documentacao/Territorium/T17_artg/24Territorium_223 -227.pdf> Acesso em: fevereiro de 2014.

UNISDR. WorldRiskIndex (WRI). Geneva, 2004. Disponível em:

<http://www.weltrisikobericht.de/uploads/media/State_of_the_art_02.pdf > Acesso em: fevereiro de 2014.

UNISDR, Terminology on Disaster Risk Reduction. Geneva, 2009. Em: Campanha Mundial de Redução de Desastres. Construindo Cidades Resilientes: Minha cidade está se preparando. Ministério da Integração Nacional. Disponível em:

<http://www.integracao.gov.br/cidadesresilientes/> Acesso em: fevereiro de 2014.

VITRUVIUS, Arquitextos. Das reformas de base ao BNH - as propostas do Seminário de Habitação e Reforma Urbana. São Paulo, 2010. Nabil Bonduki e Ana Paula Koury. Disponível em: < http://www.vitruvius.com.br/revistas/read/arquitextos/10.120/3432> Acesso em: fevereiro de 2014. 